\title{
ONLINE COMMUNITY OF INQUIRY REVIEW: SOCIAL, COGNITIVE, AND TEACHING PRESENCE ISSUES
}

\author{
D. R. Garrison \\ University of Calgary
}

\begin{abstract}
This paper explores four issues that have emerged from the research on social, cognitive and teaching presence in an online community of inquiry. The early research in the area of online communities of inquiry has raised several issues with regard to the creation and maintenance of social, cognitive and teaching presence that require further research and analysis. The other overarching issue is the methodological validity associated with the community of inquiry framework.
\end{abstract}

The first issue is about shifting social presence from socio-emotional support to a focus on group cohesion (from personal to purposeful relationships). The second issue concerns the progressive development of cognitive presence (inquiry) from exploration to resolution. That is, moving discussion beyond the exploration phase. The third issue has to do with how we conceive of teaching presence (design, facilitation, direct instruction). More specifically, is there an important distinction between facilitation and direct instruction? Finally, the methodological issue concerns qualitative transcript analysis and the validity of the coding protocol.

\section{KEYWORDS}

Social, Cognitive, and Teaching Presence, Community of Inquiry Framework, Methodological Validity, Transcript Analysis

\section{COMMUNITY OF INQUIRY}

While we have been relatively successful in identifying the properties of asynchronous learning networks, a more in-depth analysis of the educational and transactional issues requires a theoretical framework that can provide order and parsimony to the complexities of online learning. A construct that has attracted considerable attention in higher education that serves this purpose is that of a community of learners. Higher education has consistently viewed community as essential to support collaborative learning and discourse associated with higher levels of learning. Moreover, the asynchronous nature of online communication and the potential for disconnectedness has focused attention on the issue of community. In support of this perspective, there is evidence that a sense of community can be created online, although this is not a trivial challenge [1,2]. It has also been shown that sense of community is significantly associated with perceived learning [3, 4].

One of, if not the first, framework that identified both social and cognitive dimensions for studying online learning was provided by Henri [5]. This work inspired Garrison, Anderson and Archer [6] to develop a comprehensive framework as an online learning research tool (see Figure 1). The framework consisted of three elements—social, teaching and cognitive presence-as well as categories and indicators to define each of the presences and to guide the coding of transcripts (see Figure 2). It had its genesis in the work of 
John Dewey and is consistent with constructivist approaches to learning in higher education. This framework has provided significant insights and methodological solutions for studying online learning [7, 8]. The structure of the community of inquiry framework has also been confirmed through factor analysis by Garrison, Cleveland-Innes and Fung [9] and Arbaugh and Hwang [10].

\section{Community of Inquiry}

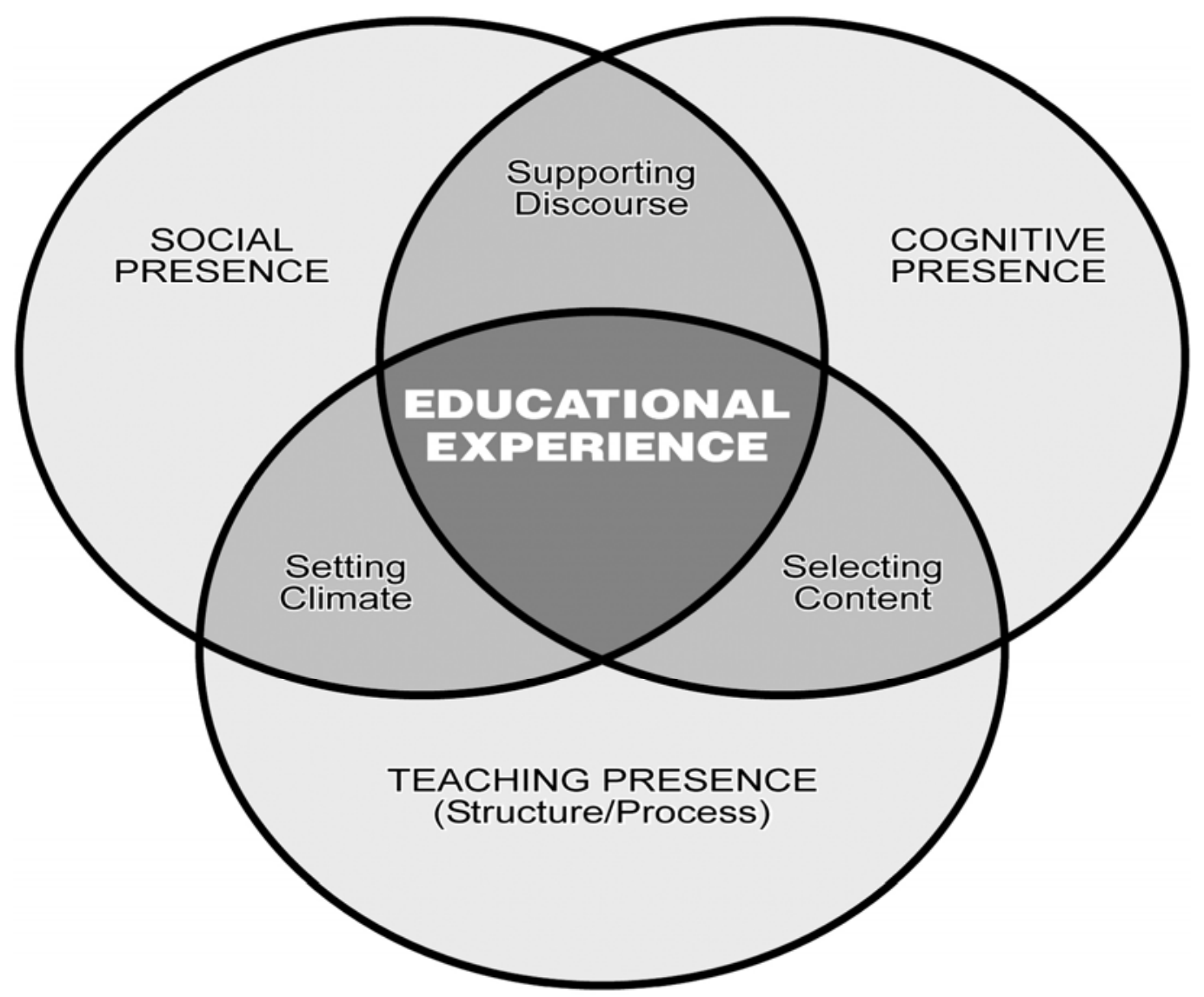

Communication Medium

Figure 1. Community of Inquiry Framework 


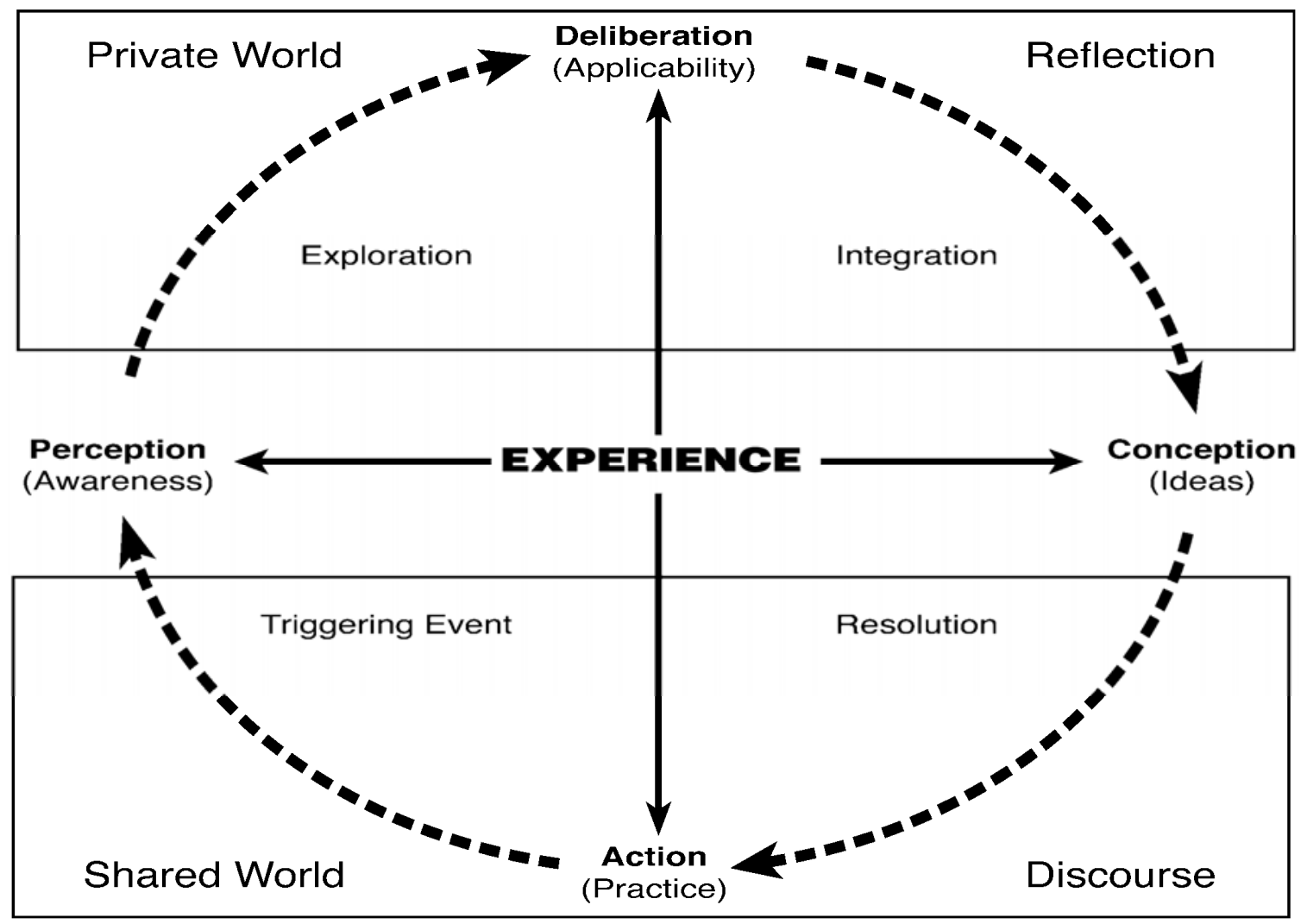

Figure 2. Practical Inquiry Model

As we shall see, the quantity of research and our understanding of each of the presences have progressed at very different rates. Each of the three key issues discussed here emerged from the online learning research literature.

\section{A. Social Presence}

Social presence is described as the ability to project one's self and establish personal and purposeful relationships. The three main aspects of social presence, as defined here, are effective communication, open communication and group cohesion (see Figure 2). Social presence attracted most of the initial online learning research attention. While this may have been an appropriate and important place to begin the study of online learning considering its asynchronous nature, much of this research was done independently of cognitive and teaching presence. It is at the intersection of social and cognitive presence where the primary issue of concern emerges. Students recognize that they are not there for purely social reasons. A sense of community is based upon common purposes and inquiry. Moreover, social presence is of less importance if the learning activities are information acquisition and there are no collaborative assignments where students can benefit from the perspectives of others [11].

The issue addressed here concerns the nature of social presence and how it needs to shift as a course of study evolves. As valuable as it is to establish effective communication and developing social bonds, it is essential that the group feels secure to communicate openly and coalesces around a common goal or purpose for a community to sustain itself [2]. Social presence must move beyond simply establishing socio-emotional presence and personal relationships. Cohesion requires intellectual focus (i.e., open and purposeful communication) and respect. For example, Swan and Shih [12] found that group cohesion is 
significantly associated with social presence and perceived learning outcomes. It is argued here that social presence in a community of inquiry must create personal but purposeful relationships. However, developing personal relationships take time and it may be that we should be focusing on open communication first. What is required is a clear understanding of how social presence shifts to support the educational objective of the community.

It was Swan [13] who first revealed the apparent shift of social presence over time in online course discussions. She reports that effective and interactive (i.e., open communication) categories increased while cohesive indicators decreased. The explanation was that it was "possible that the use of such reference became less necessary as a clear classroom community was formed." Another possible explanation addresses the fact that the discussion was more exploratory than collaborative. Cohesion may well have been a secondary issue under this circumstance. That is, collaborative tasks focused on practical outcomes may well reduce the focus on the effective and emphasize cohesive comments to achieve a successful outcome. Another consideration in interpreting these findings is the gender balance of the sample. Two thirds were female. In this regard, Arbaugh [14] has pointed to the possible differences in how male and female students communicate. This, of course, would be confounded by other issues such as community development and nature of the task. To address these issues, findings need to be interpreted in the broader context of a community of inquiry that concurrently considers social, cognitive and teaching presence issues and variables.

Contrary to the nature of the shift in social presence reported by Swan [13], Vaughan [15, 16] found that the frequency of effective and open communication comments decreased, while group cohesion comments increased. The interpretation was that effective and open communication was necessary to establish a sense of community. It was only after the social relationships were established and the group became more focused on purposeful activities did cohesive comments begin to take precedence. Not only did the focus change but it is hypothesized that because a sense of community was established, there was less need for social reinforcement. Social presence online becomes somewhat transparent as the focus shifts to academic purposes and activities.

It is important to note that the context of the Vaughan study [15] was a blended professional development community. The participants were evenly split in terms of gender and were particularly task focused. In addition, participants had the advantage to establish social presence in a face-to-face context. From a research perspective, it is not clear how much influence the blended design had on the social presence patterns reported here. Further study is required to understand exactly how social presence patterns develop. Can social presence detract from cognitive presence? Do participants in a community of inquiry naturally progress from socio-emotional connections, to establishing a climate of open communication, and then naturally engage in purposeful activities (and cohesive comments)? Or is the progression from open communication, to collaboration and cohesion, and then finally to personal relationships? Is the online environment focused primarily on academic goals [9]? Is there a qualitative difference between online and face-to-face social presence that we need to understand? Certainly, there is some evidence to suggest that the face-to-face environment can more easily provide socio-emotional support [17].

Implications arising from this issue and related research questions have practical implications for establishing and maintaining social presence in an online community of inquiry. Certainly care must be taken to encourage social interaction and to provide structure and support early on. However, social presence should not be measured simply in terms of the quantity of interaction it engenders. The purpose of social presence in an educational context is to create the conditions for inquiry and quality interaction (reflective and threaded discussions) in order to collaboratively achieve worthwhile educational goals. While effective communication may be important, it is not sufficient for educational purposes. Personal 
relationships and interaction must be defined in academic terms. Social presence for educational purposes cannot be artificially separated from the purposeful nature of educational communication (i.e., cognitive and teaching presence).

\section{B. Cognitive Presence}

Cognitive presence is defined as the exploration, construction, resolution and confirmation of understanding through collaboration and reflection in a community of inquiry. The practical inquiry model operationalizes cognitive presence and is ground in the work of Dewey [18] on reflective thinking (see Figure 3). Four phases are defined in the interests of parsimony, but in practice inquiry is not so discretely defined nor is it immutable [19].

Elements

Social Presence

Cognitive Presence

Teaching Presence

\section{Categories}

\author{
Effective Expression \\ Open Communication \\ Group Cohesion
}

Triggering Event
Exploration
Integration
Resolution

Design \& Organization

Facilitating Discourse

Direct Instruction

\section{Indicators}

\author{
Emoticons \\ Risk-free Expression \\ Encourage Collaboration
}

Sense of Puzzlement
Information Exchange
Connecting Ideas
Apply New Ideas

Setting Curriculum \& Methods

Sharing Personal Meaning

Focusing Discussion

Table 1. Some Examples of Cognitive Presence

The primary issue worthy of further exploration in terms of cognitive presence relates to the progressive development of inquiry in an online learning environment. Cognitive presence is defined in terms of a cycle of practical inquiry where participants move deliberately from understanding the problem or issue through to exploration, integration and application. The issue revealed consistently in the research findings is that it appears that inquiry invariably has great difficulty moving beyond the exploration phase [20, 21, 22, 23, 24, 25, 26, 27, 28, 29].

The question is why is it so difficult to move the process of inquiry through to resolution? Is this an artifact of the inquiry model, the contrived nature of the educational context, the communication medium, or perhaps it is the nature of the task and teaching presence (design, facilitation, and direction)? There is evidence that this pervasive finding may have more to do with aspects of teaching presence, than it is to the other possible factors. Meyer observes that integration and resolution is more demanding than exploration and, as a result, increased time for reflection is required. More specifically, she states that, "Faculty need to be more directive in their assignments ... [24]." Similarly, Celentin [20] concluded that the reason discussions do not reach the highest levels of inquiry is "strictly related to the role of the tutor". Others have also speculated that the role of the instructor is a major factor [21, 23].

In another study by Meyer, she noted that "the question initiating each of the online discussions influenced the level of the responses from students” [26]. There is evidence that the questions or tasks 
"play an important role in the type of cognitive activity evident in the discussions" [30]. When questions specifically asked students to engage in practical applications, discussions did progress to the synthesis and resolution phase. Interestingly, it was suggested that confirmation did not come from the group; the individual confirmed or rejected their own solutions [30]. If there are no shared goals requiring a collaborative solution or artifact, the transcripts of online discourse will not reveal discourse that has moved to the resolution phase. Individual reflection may take place and, if required, solutions may be posted, but there will not be any discourse. Thus, in addition to teaching presence dimensions such as facilitation and direction, as noted previously, well designed tasks are also important to see evidence of resolution in a community of inquiry.

The importance of designing appropriate tasks to move students through to resolution is also reinforced in a study specifically focused on online collaborative problem solving [31]. Where learners were specifically tasked to formulate and resolve a problem, responses were distributed throughout all of the five problem solving processes (understanding the problem, building knowledge, identifying solutions, evaluating solutions, acting on solutions). In fact, "participants engaged more in problem resolution than in problem formulation" [31] — the converse of previous cognitive presence (practical inquiry) studies. This speaks strongly to the purpose and design of the learning activity. If the activity is problem or case based, there are clear expectations, and appropriate teaching presence is provided-will participants in a community of inquiry have difficulty moving to the resolution phase?

Progression requires direction. Vaughan [15] found that design and facilitation comments decreased in online transcripts, while direct instruction comments increased. It is very important to facilitate and yet not dominate the discourse and, at the same time, be prepared to provide crucial input to ensure that the community moves to resolution. As a subject matter expert, relevant information should be interjected and diagnoses of misconceptions are crucial to productive discourse. This is a delicate and challenging balance of which an experienced teacher would or should be very cognizant. Educational leadership comes in more than one form. From an educational perspective, the distinction between facilitation and direct instruction may be worth preserving.

A supporting explanation and reason why discussions may get stalled at the exploration phase is found in the group dynamics literature. The group dynamics literature has shown that groups do not easily progress to the "performing" stage. Participants need to connect to the group and collaborative decision making proceeds along four hypothesized stages-forming, norming, storming, and performing [32]. Groups need clear goals and time to come together and function in a productive manner. The point is that groups do not naturally coalesce and move to integration and resolution phases, particularly in situations where the task and challenge is to make sense of complex and disparate information. Direction and facilitation is required to establish cohesion and ensure messages are developmental (i.e., more than "serial monologues” or personal declarations).

From the participants' perspective, moving the discussion developmentally would be enhanced considerably by enhancing the metacognitive awareness of the stages of inquiry and how this relates to the particular task at hand. One suggestion is for participants to be metacognitively aware of their contributions by requiring that they identify the level of the response. Pawan, Paulus, Yalcin, and Chang [33] recommend that students self-code their postings. They go on to say:

The strategy would encourage students to keep track of and to think about how their responses relate to the collaborative learning objectives set by their instructors. Self-coding their own roles and responses may raise students' awareness, for example, of the four cyclical categories of the practical inquiry model. 
Pawan et al. [33] also suggest that the instructor should provide direct instruction and model self-coding. In this regard, it may be helpful for the instructor to provide a metacognitive commentary as to what they are doing and why. This is clearly a teaching presence issue and challenge.

\section{Teaching Presence}

The third issue worth exploring is a validation issue. To be sure, validation of the community of inquiry and its constructs is an important issue. However, the focus here is the teaching presence construct and whether it has three distinct categories — design, facilitation and direct instruction.

Before we address the validity of the construct, it may be useful to discuss the influence of teaching presence on the success of an online learning experience. The body of evidence is growing rapidly, attesting to the importance of teaching presence for successful online learning $[12,13,15,25,27,33,34$, $35,36,37]$. The consensus is that teaching presence is a significant determinate of student satisfaction, perceived learning, and sense of community.

Interaction and discourse plays a key role in higher-order learning but not without structure (design) and leadership (facilitation and direction). For example, without explicit guidance, students will "engage primarily in "serial monologues"” [33]. Obversely, "faculty may need to be more directive in their assignments for threaded discussions, charging the participants to resolve a particular problem, and pressing the group to integrate their ideas..." [25]. Murphy is clear "that in order for the highest-level collaborative processes to occur within an OAD [online asynchronous discussion], there must be explicit strategies or techniques aimed at promoting these processes” [27]. Similarly, Gilbert and Dabbagh concluded that "the number and type of facilitator postings also increased the level of interaction between students" [38]. They make it clear that structure and facilitation have a significant influence on discourse.

That said, it is important to understand the composition of teaching presence. Whether there are two or three distinct categories is more than a theoretical issue. It has practical implications for a community of inquiry and supporting social and cognitive presence. A recent study questioned whether there are three categories corresponding to the hypothesized structure. Shea [4] completed an extensive study of teaching presence and online learning. After factor analyzing survey data of over 2000 students across multiple institutions, it was concluded that a two factor solution was most interpretable. The two factors were labeled design and "directed facilitation". The latter apparently being the amalgamation of facilitation and direct instruction. It should be noted as well that the directed facilitation factor contributed the most to predicting a sense of community and learning.

The key point in this study is that this is the perspective of students. One interpretation is that students may not distinguish between facilitation and direct instruction. This would not seem to be surprising. To students this is a subtle distinction. Students do not come at this from an educational perspective and a full consideration of the nature of critical discourse. From a teaching perspective, this is the difference between dialogue and discourse [39]. Facilitation supports dialogue with minimal shaping of the course of the discussion. Discourse, on the other hand, is disciplined inquiry that requires a knowledgeable teacher with the expectation that discourse progresses in a collaborative constructive manner and students gain an awareness of the inquiry process.

On the other hand, a study of MBA students did validate the categories of teaching presence [10]. This survey of 191 students across multiple courses used an instrument based on the Shea, Fredericksen, Pickett and Pelz [40] instrument. Thus, using essentially the same instrument and using a confirmatory 
factor analysis, Arbaugh and Hwang "validated the three components of teaching presence as posited in the...Community of Inquiry model” [10]. Beyond the fact that the teaching presence construct was validated, the interesting question here is why this study confirmed the three components of teaching presence construct, and the Shea et al. [40] study found only two when both used virtually the same instrument? One explanation may be the nature of the analysis. Another explanation may be related to the fact that "all three components are distinct yet highly correlated with each other" [40]. That is, the design (curriculum, goals, method) may have a great influence on how the students perceive other components of teaching presence. Similarly, social and cognitive presences will also influence teaching presence and how it is perceived. As noted previously, another explanation to these divergent findings may be due to student perspectives. That is, undergraduates may not be sophisticated enough to distinguish between facilitation and direct instruction.

\section{CODING AND VALIDITY}

The community of inquiry framework has provided a useful tool and approach to studying online learning. The methodology to date can best be described as an exploratory qualitative approach to provide "insights for the purposes of constructing meaningful propositions to be explored in further research" [8]. This research begins with a credible framework and, therefore, is not inductive theory building. To date, much of the research could be best described as interpretivist, in that there is an attempt to understand interactions through text analysis [41]. While issues of validity are relevant to qualitative transcript analysis,

... assigning frequencies to the classifications is an aid in understanding patterns, this does not make it a quantitative, inferential statistical procedure. We are in the early stages of understanding and explaining the complexities of online conferencing and educational discourse. The goal is descriptive, not predictive [8].

That said, the question has been raised about moving the validity of the coding protocol to a quantitative approach. Rourke and Anderson argue for a quantitative content analysis technique and question the rigor of the research in this area. They frame the argument as description versus inference. Their point is that much of the online transcript analysis is descriptive and at some point there needs to be a transition to inference and "a richer definition of test validity" [42]. Rourke and Anderson [42] state that if researchers wish to proceed to the inferential, it must be done mindfully and with understanding as to the steps required to validate coding protocols.

For purposes of discussion we make a distinction between the broad theoretical framework and specific coding schemes, notwithstanding that they are intimately related. With regard to the validity of the theoretical framework, other constructs have been proposed [26, 31, 43] that are not entirely dissimilar to elements of the community of inquiry framework. It would seem, however, that the community of inquiry framework offers a more comprehensive perspective capable of identifying interaction effects among social, cognitive and teaching presence dynamics. There has been surprisingly little discussion about the reasonableness and usefulness of the community of inquiry framework in studying online learning. A key question is whether the three elements capture the core dynamics of a community of inquiry?

On the other hand, there is greater diversity of practice with regard to coding protocols [44]. The issue here is whether the elements have been well defined and the categories are valid (representative of the element). Do the categories fully describe the elements (i.e., presences) of the community of inquiry? Should different protocols be considered for certain research questions? Shifting our focus to the indicators, certainly the indicators must reliably reflect the appropriate category. That is, do the indicators reflect the essence of the categories? Are the indicators of sufficient detail and range to be useful in coding? 
There is the question, however, as to why we would want to code at the indicator level? Coding at the indicator level is difficult [45]. Is it not a bit premature considering the early stage of this research and testing of the framework? What research questions would coding at the indicator level answer? How does being able to distinguish among the indicators add to the validity of the model? Are indicators too context specific to expect a standard set of indicators across all online educational environments?

Other coding issues are what unit of analysis (e.g., sentence, paragraph, message, or theme) should be employed? While there has been some discussion around this issue [8, 46, 47] it remains a crucial but challenging decision. Certainly the research question and context will influence this decision. The importance of training for reliability is another important reliability and validity issue where more attention would be beneficial. In summary, what is clear is that much work remains in addressing coding schemes and validating the community of inquiry framework.

Finally, are we ready to emerge from the early exploratory and descriptive phase of researching online communities of inquiry? The time may be right to transition to a phase that utilizes both qualitative and quantitative approaches to studying online learning communities. The focus will likely shift to developing and employing psychometrically sound instruments capable of studying larger inter-disciplinary and inter-institutional samples over time. The foundation for this shift has been laid. Swan and Shih [12] have developed a sound social presence survey based on the work of Gunawardena and Zittle [48] and Richardson and Swan [49]. Arbaugh and Hwang [10] have validated a teaching presence survey questionnaire based on the work of Shea et al. [40]. Preliminary items reflecting the cognitive presence construct have been offered by Garrison et al. [50]. The theoretical framework and research to date would support development of these instruments and their use to study online communities of inquiry. Both qualitative and quantitative efforts will contribute to the refinement of the community of inquiry framework and the categories and indicators of its elements/constructs [8].

\section{CONCLUSION}

The issues discussed previously are not just theoretical issues of interest to researchers. They have important practical pedagogical implications. Understanding the role of social presence is essential in creating a community of inquiry and in designing, facilitating, and directing higher-order learning. This is not a simple one-off task. Balancing socio-emotional interaction, building group cohesion and facilitating and modeling respectful critical discourse is essential for productive inquiry. As Baker discovered, "instructor immediacy [i.e., teaching presence] was more predictive of effective and cognitive learning" than "whether students felt close to each other" [51]. Some cohorts are academically focused and do not need or want to engage in a virtual social space [52]. These cohorts usually have well defined practical outcomes that are collaboratively based. As important as social presence may be, a community of inquiry is associated with a sense of common purpose and cognitive presence.

A community of inquiry needs to have clear expectations as to the nature of critical discourse and their postings. Participants need to be aware of the academic objectives, the phases of inquiry, and the level of discourse. These educational challenges raise the importance and role of teaching presence. The distinction between facilitation and direction must also be clear from a design perspective. Teaching presence must consider the dual role of both moderating and shaping the direction of the discourse. Both are essential for a successful community of inquiry.

The previous discussion raises many challenges with regard to social, cognitive and teaching presence as well as coding and validity demands. While the community of inquiry framework has shown itself to be 
useful in guiding research into online learning, the more we understand online learning the more we raise other questions and issues (not unlike other areas of research). The goal here has been to begin documenting the issues and challenges for others to address and build upon.

\section{ABOUT THE AUTHOR}

D. Randy Garrison is currently the Director of the Teaching and Learning Centre and a professor in the Faculty of Education at the University of Calgary. Dr. Garrison has published extensively on teaching and learning in higher, adult and distance education contexts. Dr. Garrison's most recent book (in press) is titled Blended Learning in Higher Education.

\section{REFERENCES}

1. Rovai, A. P. Development of an instrument to measure classroom community. The Internet and Higher Education 5(3): 197-211, 2002.

2. Thompson, T. L. and C. J. MacDonald. Community building, emergent design and expecting the unexpected: Creating a quality eLearning experience. The Internet and Higher Education 8(3): 233249, 2005.

3. Rovai, A. P. Sense of community, perceived cognitive learning, and persistence in asynchronous learning networks. The Internet and Higher Education 5(4): 319-332, 2002.

4. Shea, P. A study of students' sense of learning community in online environments. Journal of Asynchronous Learning Networks 10(10): 2006. http://www.sloan-c.org/publications/jaln/v10n1 /v10n1_4shea_member.asp.

5. Henri, F. Computer conferencing and content analysis. In: A. R. Kaye (Ed.), Collaborative learning through computer conferencing: The Najaden papers, Berlin: Springer-Verlag, 117-136, 1992.

6. Garrison, D. R., T. Anderson and W. Archer. Critical inquiry in a text-based environment: Computer conferencing in higher education. The Internet and Higher Education 2(2-3): 87-105, 2000.

7. Garrison, D. R. and W. Archer. A Community of Inquiry Framework for Online Learning. In: M. Moore (Ed.), Handbook of distance education. New York: Erlbaum, 2003.

8. Garrison, D. R., M. Cleveland-Innes, M. Koole and J. Kappelman. Revisting methodological issues in the analysis of transcripts: Negotiated coding and reliability. The Internet and Higher Education 9(1): 1-8, 2006.

9. Garrison, D. R., M. Cleveland-Innes and T. Fung. Student role adjustment in online communities of inquiry: Model and instrument validation. Journal of Asynchronous Learning Networks 8(2): 6174, 2004. Retrieved August 13, 2005 from http://www.sloan-c.org/publications/jaln/v8n2 /pdf/v8n2_garrison.pdf.

10. Arbaugh, J. B. and A. Hwang. Does "teaching presence" exist in online MBA courses? The Internet and Higher Education 9(1): 9-21, 2006.

11. Picciano, A. G. Beyond student perceptions: Issues of interaction, presence, and performance in an online course. Journal of Asynchronous Learning Networks 6(1): 2002. Retrieved January, 6, 2006 from http://www.sloan-c.org/publications/jaln/v6n1/pdf/v6n1_picciano.pdf.

12. Swan, K. and L. F. Shih. On the nature and development of social presence in online course discussions. Journal of Asynchronous Learning Networks 9(3): October 2005. http://www.sloanc.org/publications/jaln/v9n3/pdf/v9n3_swan.pdf.

13. Swan, K. Developing social presence in online discussions. In: S. Naidu (Ed.), Learning and teaching with technology: Principles and practices, 147-164. London: Kogan Page, 2003.

14. Arbaugh, J. B. Is there an optimal design for on-line MBA courses? Academy of Management Learning \& Education 4(2): 135-149, 2005. 
15. Vaughan, N. D. Investigating how a blended learning approach can support an inquiry process within a faculty learning community. Doctoral dissertation, University of Calgary, 2004.

16. Vaughan, N. and D. R. Garrison. How blended learning can support a faculty development community of inquiry. Journal of Asynchronous Learning Networks 10(4): December 2006.

17. Abrams, Z. Asynchronous CMC, Collaboration and the development of critical thinking in a graduate seminar in applied linguistics. Canadian Journal of Learning Technology 31(2): 23-47, 2005.

18. Dewey, J. How we think (Rev. Ed.). Boston: D.C. Heath, 1933.

19. Garrison, D. R. and T. Anderson. E-Learning in the $21^{\text {st }}$ century: A framework for research and practice. London: Routledge/Falmer, 2003.

20. Celentin, P. (unpublished). Online training: Analysis of interaction and knowledge building patterns among foreign language teachers.

21. Garrison, D. R., T. Anderson and W. Archer. Critical thinking and computer conferencing: A model and tool to assess cognitive presence. American Journal of Distance Education 15(1): 7-23, 2001.

22. Kanuka, H. and T. Anderson. Online social interchange, discord, and knowledge construction. Journal of Distance Education 13(1): 57-75, 1998.

23. Luebeck, J. L. and L. R. Bice. Online discussion as a mechanism of conceptual change among mathematics and science teachers. Journal of Distance Education 20(2): 21-39, 2005.

24. McKlin, T., S. W. Harmon, W. Evans and M. G. Jones. Cognitive presence in web-based learning: A content analysis of students' online discussions. ITForum Paper \#60, 2002. Retrieved October 11, 2005 from http://it.coe.uga.edu/itforum/paper60/paper60.htm.

25. Meyer, K. A. Face-to-face versus threaded discussions: The role of time and higher-order thinking. Journal of Asynchronous Learning Networks 7(3): 55-65, 2003.

26. Meyer, K. A. Evaluating online discussions: Four different frames of analysis. Journal of Asynchronous Learning Networks 8(2): 101-114, 2004.

27. Murphy, E. Recognizing and promoting collaboration in an online asynchronous discussion. British Journal of Educational Technology 35(4): 421-431, 2004.

28. Newman, D. R., C. Johnson, C. Cochrane and B. Webb. An experiment in group learning technology: Evaluating critical thinking in face-to-face and computer-supported seminars. Interpersonal Computing and Technology 4(1): 57-74, 1996. Retrieved March 30, 2005 from http://www.helsinki.fi/science/optek/1996/n1/newman.txt.

29. Vaughan, N. and D. R. Garrison. Creating cognitive presence in a blended faculty development community. Internet and Higher Education 8: 1-12, 2005.

30. Arnold, N. and L. Ducate. Future foreign language teachers' social and cognitive collaboration in an online environment. Language Learning \& Technology 10(1): 42-66, 2006. Retrieved January 14, 2006 from http://lit.msu.edu/vol10num1/pdf/arnoldducate.pdf.

31. Murphy, E. Identifying and measuring ill-structured problem formulation and resolution in online asynchronous discussions. Canadian Journal of Learning and Technology 30(1): 5-20, 2004b.

32. Tuckman, B. W. and M. C. Jensen. Stages of Small-Group Development Revisited. Group and Organization Studies 2: 419-427, 1977.

33. Pawan, F., T. M. Paulus, S. Yalcin and C. Chang. Online learning: Patterns of engagement and interaction among in-service teachers. Language Learning \& Technology 7(3): 119-140, 2003.

34. Garrison, D. R. and M. Cleveland-Innes. Facilitating cognitive presence in online learning: Interaction is not enough. American Journal of Distance Education 19(3): 133-148, 2005.

35. Shea, P. J., A. M. Pickett and W. E. Pelz. Enhancing student satisfaction through faculty development: The importance of teaching presence. In: J. Bourne \& J. C. Moore (Eds.), Elements of Quality Online Education: Into the Mainstream, Vol. 5, 39-59. Needham, MA: Sloan-C, 2004.

36. Varnhagen, S., D. Wilson, E. Krupa, S. Kasprzak and V. Hunting. Comparison of student experiences with different online graduate courses in health promotion. Canadian Journal of Learning and Technology 31(1): 99-117, 2005. 
37. Wu, D. and S. R. Hiltz. Predicting learning from asynchronous online discussions. Journal of Asynchronous Learning Networks 8(2): 139-152, 2004.

38. Gilbert, P. K. and N. Dabbagh. How to structure online discussions for meaningful discourse: A case study. British Journal of Educational Technology 36(1): 5-18, 2005.

39. Rourke, L. and H. Kanuka. (unpublished manuscript). Barriers to online critical discourse.

40. Shea, P. J., E. E. Fredericksen, A. M. Picket and W. E. Pelz. A preliminary investigation of "teaching presence" in the SUNY learning network. In: J. Bourne and J. C. Moore (Eds.), Elements of Quality Online Education: Practice and Direction, Vol. 4, 279-312. Needham, MA: Sloan-C, 2003.

41. Miles, M. B. and A. M. Huberman. Qualitative Data Analysis: An Expanded Sourcebook. Thousand Oaks, CA: Sage, 1994.

42. Rourke, L. and T. Anderson. Validity in Quantitative Content Analysis. Educational Technology Research and Development 52(1): 5-18, 2004.

43. Gunawardena, C., C. Lowe and T. Anderson. Analysis of a global online debate and the development of an interaction analysis model for examining social construction of knowledge in computer conferencing. Journal of Educational Computing Research 17(4): 379-431, 1997.

44. Marra, R. M., J. L. Moore and A. K. Klimczak. Educational Technology Research \& Development 52(2): 23-40, 2004.

45. Murphy, E. and J. Ciszewska-Carr. Sources of difference in reliability: Identifying sources of difference in reliability in content analysis of online asynchronous discussions. International Review of Research in Open and Distance Learning 6(2): 2005. Retrieved January 17, 2006 from http://www.irrodl.org/index.php/irrodl/article/view/233/408.

46. Fahy, P. J. Addressing some common problems in transcript analysis. International Review of Research in Open and Distance Learning 1(2): 2001. Retrieved June 20, 2005 from http://www.irrodl.org/index.php/irrodl/article/view/321/530.

47. Rourke, L., T. Anderson, D. R. Garrison and W. Archer. Methodological Issues in the Content Analysis of Computer Conference Transcripts. International Journal of Artificial Intelligence in Education 12(1): 8-22, 2001.

48. Gunawardena, C. and F. Zittle. Social presence as a predictor of satisfaction within a computer mediated conferencing environment. American Journal of Distance Education 11(3): 8-26, 1997.

49. Richardson, J. C. and K. Swan. Examining social presence in online courses in relation to students' perceived learning and satisfaction. Journal of Asynchronous Learning Networks 7(1): 6888, 2003.

50. Garrison, D. R. and H. Kanuka. Blended Learning: Uncovering its Transformative Potential in Higher Education. The Internet and Higher Education 7(2): 95-105, 2004.

51. Baker, J. Instructor immediacy increases student enjoyment, perception of learning. Online Classroom, September 2003.

52. McPherson, M. and M. B. Munes. The failure of a virtual social space (VSS) designed to create a learning community: Lessons learned. British Journal of Educational Technology 35(3): 305-321, 2004. 